\title{
Gene expression regional differences in human subcutaneous adipose tissue
}

Angelina Passaro ${ }^{1,2^{*}}$ D , Maria Agata Miselli ${ }^{1,2}$, Juana Maria Sanz ${ }^{2}$, Edoardo Dalla Nora ${ }^{1,2}$, Mario Luca Morieri ${ }^{1,2}$, Rossella Colonna ${ }^{1,2}$, Rado Pišot ${ }^{3}$ and Giovanni Zuliani ${ }^{1,2}$

\begin{abstract}
Background: Accumulation of visceral adipose tissue (VAT) is clearly associated with an increased risk of obesity-related diseases and all-cause mortality, whereas gluteal subcutaneous fat accumulation (g-SAT) is associated with a lower risk. The relative contribution, in term of cardiovascular risk, of abdominal subcutaneous adipose tissue (a-SAT) is still controversial with studies showing both a detrimental effect and a protective role.

Animal and in vitro studies demonstrated that adipocytes from visceral and subcutaneous depots have distinct morphological, metabolic and functional characteristics. These regional differences have a key role in the pathogenesis of obesity-related diseases. There is recent evidence that differentiation between upper-body and lower-body adipose tissues might be under control of site-specific sets of developmental genes, such as Homebox (HOX) genes, a group of related genes that control the body plan of an embryo along the anterior-posterior axis. However, the possible heterogeneity between different subcutaneous regions has not been extensively investigated.

Here we studied global mRNA expression in g-SAT and a-SAT with a microarray approach. RNA was isolated from g-SAT and a-SAT biopsy, from eight healthy subjects, and hybridized on RNA microarray chips in order to detect regional differences in gene expression.

Results: A total of 131 genes are significantly and differently $(>1.5$ fold change, $p<0.05)$ expressed in a-SAT and g-SAT. Expression profiling reveals significant differences in expression of several HOX genes.

Interestingly, two molecular signature of visceral adipocyte lineage, homebox genes HOXA5 and NR2F1, are up-regulated in a-SAT versus g-SAT by a 2.5 fold change.

Conclusions: Our study shows that g-SAT and a-SAT have distinct expression profiles. The finding of a different expression of HOX genes, fundamental during the embryo development, suggests an early regional differentiation of subcutaneous adipose depots. Moreover, the higher expression of HOXA5 and NR2F1, two molecular signatures of visceral adipocytes, in a-SAT suggests that this subcutaneous adipose depot could be more similar to VAT than g-SAT.

Our data suggest that we should look at SAT as composed of distinct depots with possibly different impact in obesity associated metabolic complications.
\end{abstract}

Keywords: Obesity, Microarray, Adipose tissue, SAT, VAT, Homeobox genes

\footnotetext{
* Correspondence: psn@unife.it

${ }^{1}$ Azienda Ospedaliero Universitaria di Ferrara, Ferrara, Italy

${ }^{2}$ Department of Medical Sciences, Section of Internal Medicine and

CardioRespiratory, University of Ferrara, Ferrara, Italy

Full list of author information is available at the end of the article
}

(c) The Author(s). 2017 Open Access This article is distributed under the terms of the Creative Commons Attribution 4.0 International License (http://creativecommons.org/licenses/by/4.0/, which permits unrestricted use, distribution, and reproduction in any medium, provided you give appropriate credit to the original author(s) and the source, provide a link to the Creative Commons license, and indicate if changes were made. The Creative Commons Public Domain Dedication waiver (http://creativecommons.org/publicdomain/zero/1.0/) applies to the data made available in this article, unless otherwise stated. 


\section{Background}

Obesity, defined as abnormal or excessive fat accumulation, increases risks for multiple metabolic diseases, such as type 2 diabetes (T2DM) and cardiovascular disease (CVD) [1].

Adipose tissue is a highly specialized loose connective tissue able to store large quantities of triacylglycerol (triglycerides) and fat-soluble substances. On a cytological level, adipose tissue is heterogeneous: the main parenchymal cells are the white adipocytes. White adipocytes are characterized by a unilocular lipid droplet occupying $95 \%$ of the cell volume, and a 'squeezed' nucleus. Despite adipocytes represent $\sim 90 \%$ of the tissue volume, other cells type are present in adipose tissue such as preadipocytes, endothelial cells, pericytes, multipotent stem cells and immune system cells (macrophages, Tcells, neutrophils, lymphocytes).

It is generally regarded as a tissue without a specific anatomy. However, there are increasing data supporting the idea that adipose depots are organized to form a large organ with discrete anatomy, specific vascular and nerve supplies, complex cytology, and high physiological plasticity [2]. This organ is made up of several depots located in two main compartments of the body: subcutaneous adipose tissue (SAT) and visceral adipose tissues (VAT). SAT represents over $80 \%$ of total body fat and is most commonly distinguished in abdominal (a-SAT), gluteal-femoral depots (g-SAT). VAT, which is mostly associated with digestive organs, includes omental, mesenteric and epiploic adipose tissue depots. The adipose organ contributes to many fundamental biological functions: thermogenesis, lactation, immune responses and obviously energy balance and energy substrates partitioning.

More than 50 years ago J. Vague observed that not only fat mass but also adipose tissue distribution is clearly linked to CVD risk. Central obesity, characterized by an increase in VAT and abdominal SAT, confers increased risk of CVD, insulin resistance, T2DM and even all-cause mortality. On the other hand peripheral obesity, characherized by preferential accumulation of gluteo-femoral fat is associated with lower risk and may be protective [3-6].

At an anatomical level, different depots differ in cellular composition, microvasculature, innervation, metabolic characteristics, extracellular matrix composition [7]. Moreover different studies showed a different pattern of adipokines secretion and endocrine function between abdominal and lower-body adipose [8-14]. However, the relative contribution of abdominal subcutaneous adipose depot to increased cardiovascular is still controversial $[15,16]$.

The heterogeneity between different subcutaneous depots has also been investigated: abdominal subcutaneous adypocytes differ from femoral ones in term of proliferation [17], differentiation [18] and fatty acid release and accumulation capacity [19, 20]. Different adrenergic stimulation response [21, 22] and sexual hormones influence $[19,23]$ have also been reported, while data on possible differences in insulin effect among different subcutaneous depots are inconclusive [24].

Several studies suggest that different fat depots could arise from distinct precursors, derived from mesenchymal stem cells, with inherently different proliferative and adipogenic properties [25]. Gene expression profiling has identified different molecular signature of adipocyte lineage commitment. These genes, such as nuclear transcriptional receptor protein coding gene NR2F1 (Nuclear Receptor subfamily 2 group F member 1 or Coup-TF1), seem to play a major role in early cell-fate determination [26]. Similarly, another study underpinned that the profound functional differences between the upper-body and lower-body adipose tissues might be under control of site-specific sets of developmental genes, such as Homebox (HOX) genes, a group of related genes that control the body plan of an embryo along the anterior-posterior axis [27].

Here we studied global mRNA expression in gluteal and abdominal adipose tissues from eight healthy subjects, with a microarray approach, in order to detect regional differences in gene expression.

\section{Results}

The anthropometric and metabolic characteristics of participants are shown in Table 1.

In the microarray analysis, 42.405 probes were detected in abdominal and gluteal adipose tissues. Considering 1.5 fold change as lower limit, a total of 181 probes were differentially expressed between the abdominal and gluteal depot, corresponding for a total of 131 coding genes; 49 genes were up-regulated in abdominal versus gluteal adipose tissue (Table 2). Most of the expression differences were modest, $>80 \%$ in $1.5-3$ fold change range. Hierarchical clustering analysis of gene expression profiles in subcutaneous abdominal and gluteal adipose tissues of these 8 healthy subjects is represented in Fig. 1.

Table 1 Characteristics of all participants

\begin{tabular}{ll}
\hline Characteristic & Mean \pm SD \\
\hline Age (years) & $60 \pm 3$ \\
BMI (Kg/mq) & $25.0 \pm 3.0$ \\
FM (\%) & $21.4 \pm 6.5$ \\
Total-C (mg/dl) & $218.6 \pm 24.2$ \\
Triglycerides (mg/dl) & $147.9 \pm 72$ \\
HDL-C (mg/dl) & $43.7 \pm 5.8$ \\
LDL-C (mg/dl) & $145.3 \pm 25.2$ \\
\hline
\end{tabular}




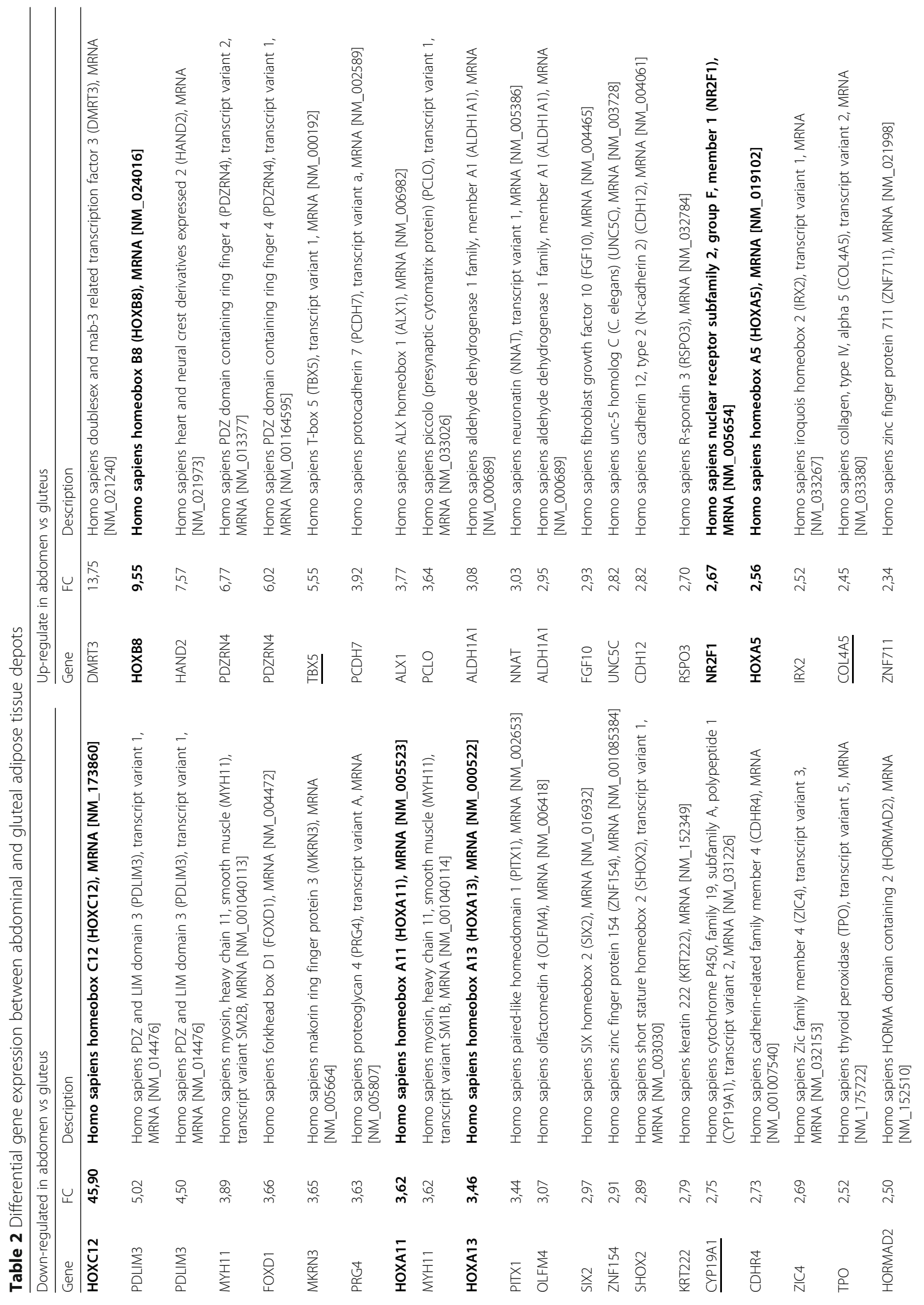




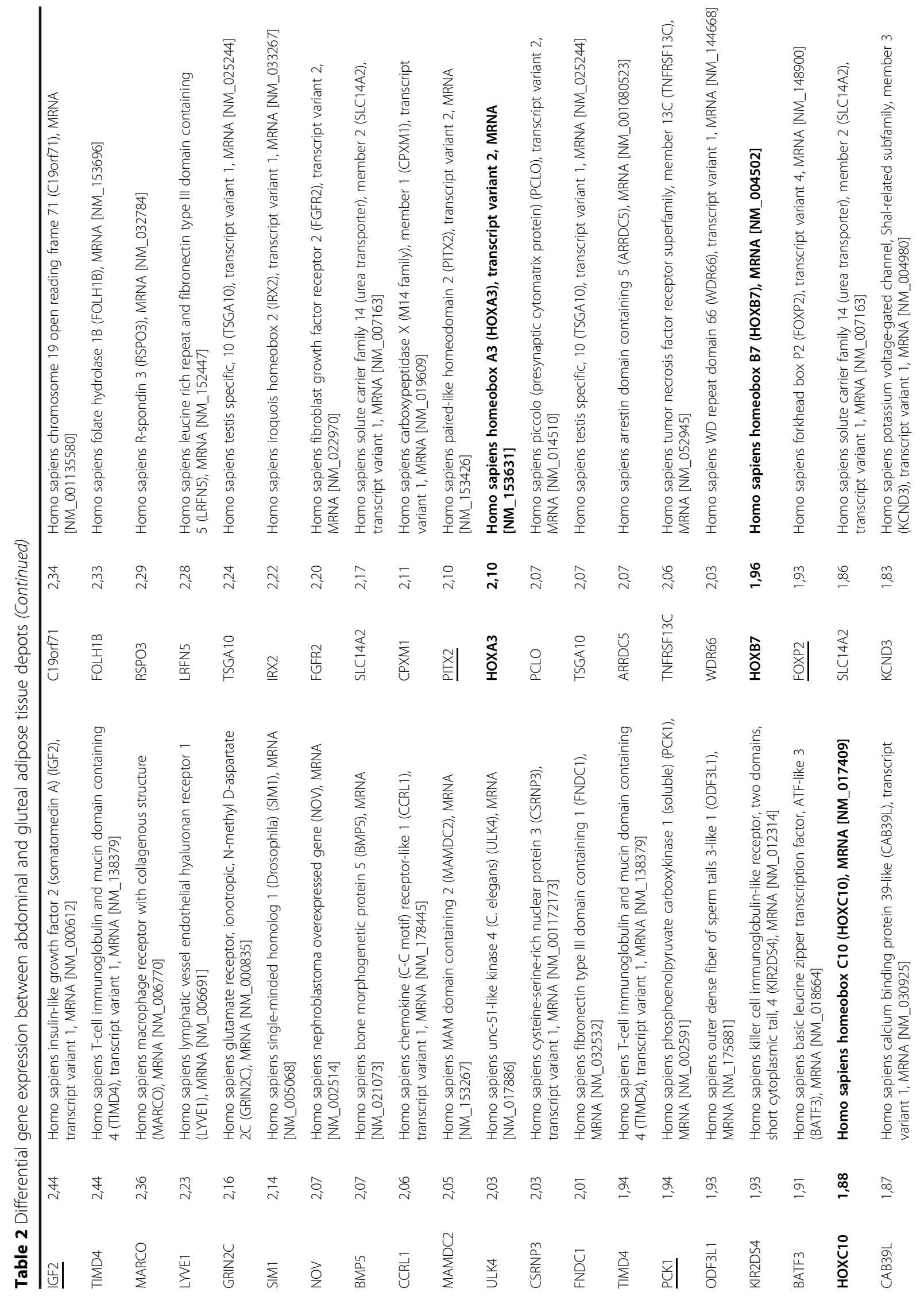




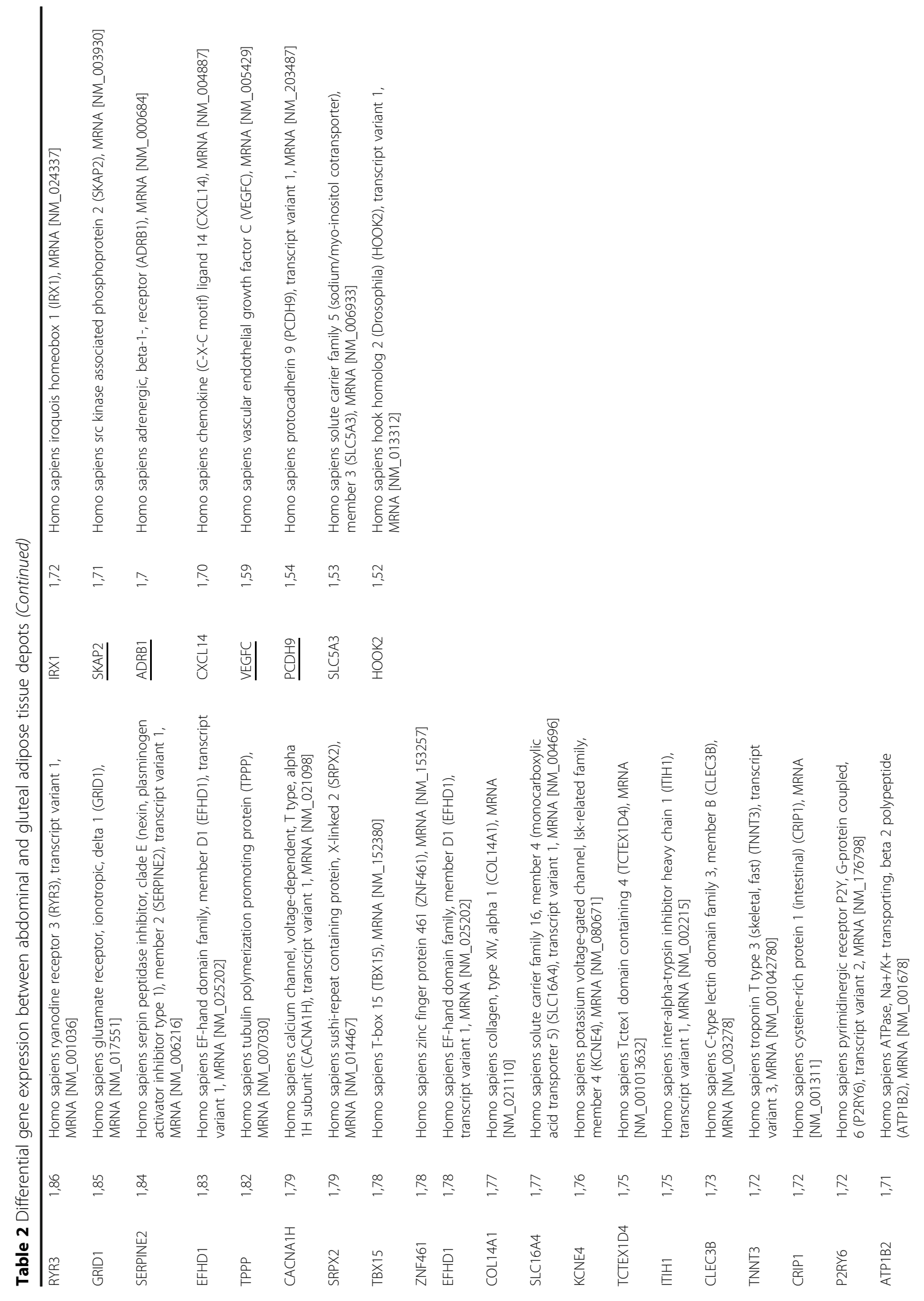




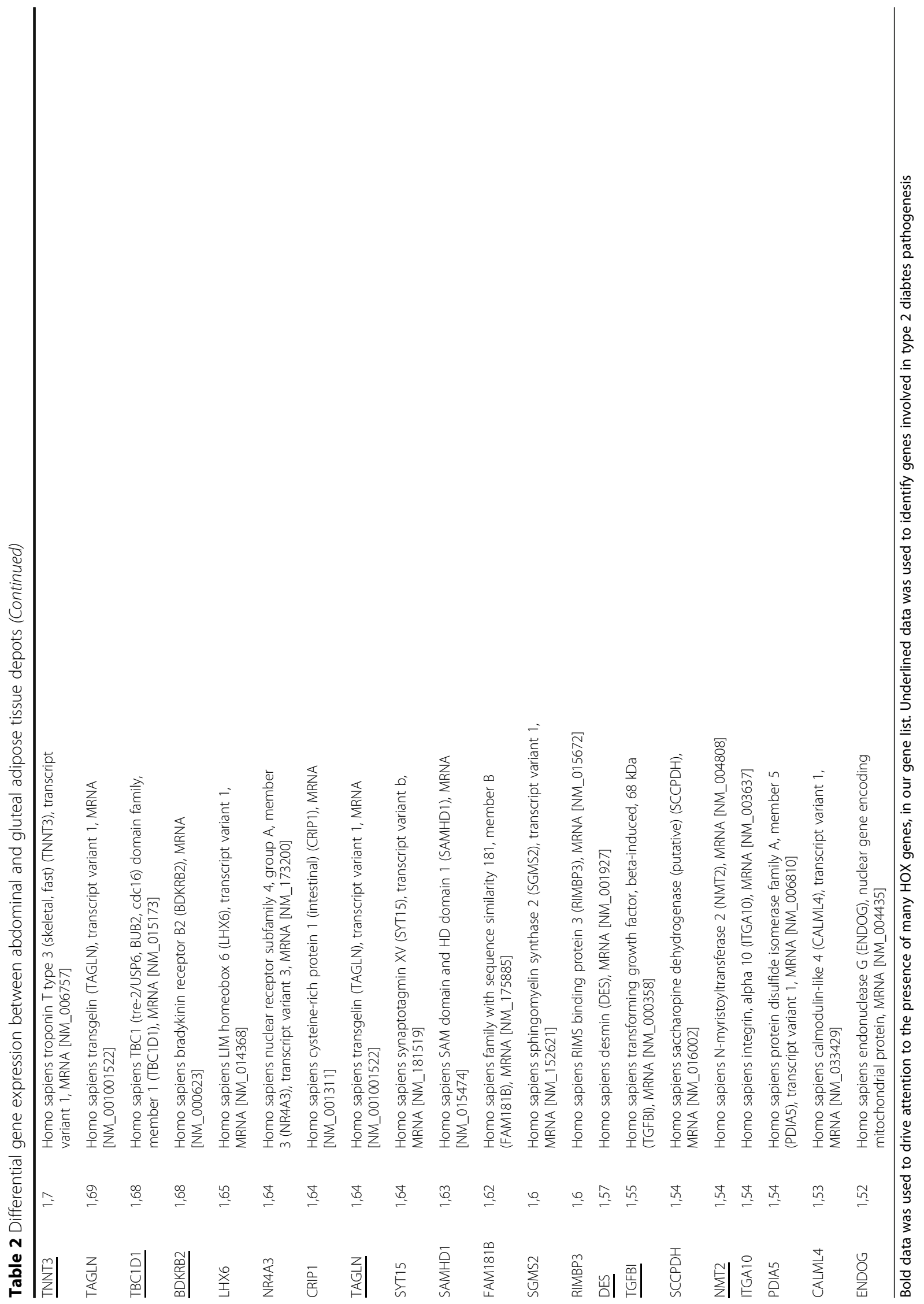




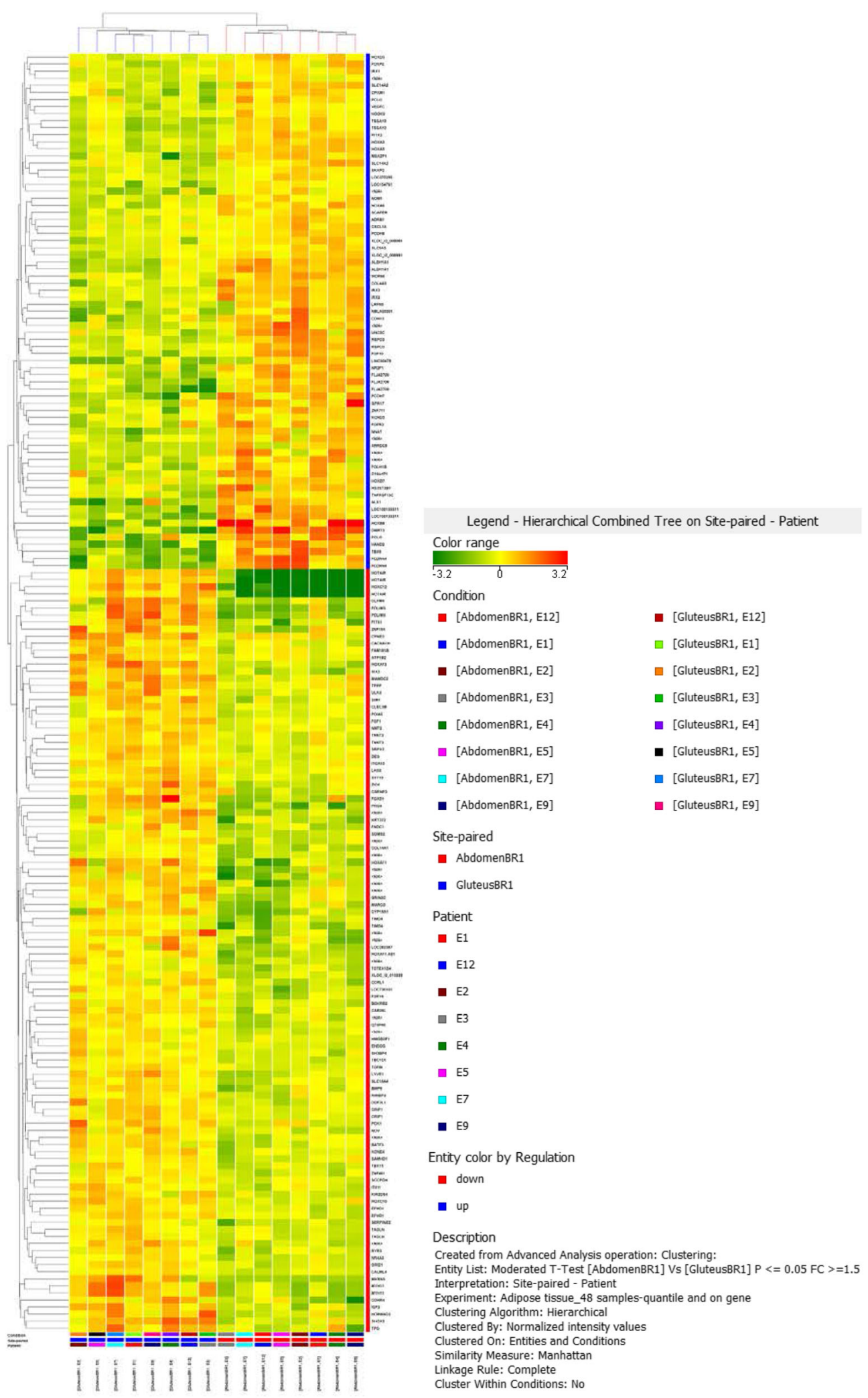

Fig. 1 Gene clustering in abdominal and gluteal adipose tissue 
We identified several HOX genes expression differences between gluteal and abdominal depots (bold in Table 2). Mean fold change for HOX gene group was 8.88 (range from 1.88 to 45.90 ), compared to 2.84 mean fold change of entire group of differentially expressed genes. HOXA3, HOXA5, HOXB7, HOXB8, were up-regulated in the abdominal depot, while HOXA11, HOXA13, HOXC10, HOXC12 were up-regulated in gluteal adipose tissue, with HOXC12 expression being almost 50 times overexpressed in gluteal vs abdominal adipose tissue.

NR2F1 was up-regulated in abdominal vs gluteal adipose tissue (FC 2.67).

In silico analysis with bioinformatics database support (DAVID gene functional classification tool) showed that 18 out of 131 coding genes have been previously involved in type 2 diabetes pathogenesis (underlined in Table 2): TBX5, COL4A5, PITX2, FOXP2, SKAP2, ADRB1, VEGFC, $\mathrm{PCDH} 9$ were up-regulated in the abdominal depot, while CYP19A1, IGF2, PCK1, TNNT3, TBC1D1, BDKRB2, TAGLN, DES, TGFBI, NMT2 were up-regulated in gluteal adipose tissue.

\section{Discussion}

Adipose tissue is considered as the largest endocrine organ in humans, and includes numerous discrete anatomical depots. There is evidence that different adipose tissue depots have different morphology, physiology and adipokine profiles. Although depot differences in adipocyte metabolism and endocrine function are clearly important in etiology of obesity related diseases, the relative contribution of VAT compared to abdominal subcutaneous is still controversial. Moreover, there is little evidence of in vivo or in vitro differences between different subcutaneous adipose depot.

The advent of new technology that allows the characterization of entire transcriptomes has permitted to look from another perspective to adipose tissue depots heterogeneity and led to the hope that the properties of adipose tissue and differences between adipose tissue depots might be revealed to help discover new therapeutic avenues.

Indeed, expression profiling has revealed significant differences in expression of hundreds of genes between different depots of adipose tissue in both rodents and humans [28-30], particularly developmental and patterning genes involved in cell differentiation, organogenesis, antero-posterior or dorso-ventral patterning. These findings not only have contributed to help explain the distinct impact of these depots on the development of metabolic complications but also have suggested possible differences in developmental origin of these fat cells [31].

Adipose tissue has a mesodermal origin. A layer of cells between the primitive endoderm and ectoderm migrates and spreads along the antero-posterior and dorso-ventral axes of the developing embryo generating the axial, intermediate, lateral plate, and paraxial mesoderm. Each of these embryologic tissues eventually gives rise to local adipose tissue. Vertebrate embryonic patterning and evolution of mesodermal tissues such as fat are controlled by several conserved developmental signaling systems. The mesenchimal stem cell gives origin to an early precursor, the adipoblast, which develops into committed preadipocytes that under appropriate stimuli differentiate into mature adipocytes of different types.

In more recent studies, the differences in gene expression pattern have been shown to persist even after in vitro differentiation of preadipocytes, suggesting that the differences are independent of extrinsic factors and that different adipocyte progenitors are programmed through epigenetic modulation during early development, participating in determining functional differences observed between different adipose tissue depots [27].

The most frequently observed differences in gene expression involve HOX genes, a subset of Homeobox genes. A Homeobox is a DNA sequence, around 180 base pairs long, found within genes that are involved in the regulation of patterns of anatomical development (morphogenesis) in animals, fungi and plants. These genes encode Homeodomain protein products that are transcription factors sharing a characteristic protein fold structure that binds DNA. Through the DNA-recognition properties of the Homeodomain, Homeoproteins are believed to regulate the expression of targeted genes and direct the formation of many body structures during early embryonic development. Many Homeodomain proteins induce cellular differentiation by initiating the cascades of coregulated genes required to produce individual tissues and organs. Thus, Homeobox genes are critical in the establishment of body axes during embryogenesis. The HOX genes in humans are organized in four chromosomal clusters: HOXA, HOXB, HOXC and HOXD.

In a 2006 study from Gesta et al., gene expression profiling has revealed that intraabdominal (visceral) adipocytes express higher levels of HOXA5, HOXA4, HOXC8 and NR2F1, whereas subcutaneous fat has higher levels of HOXA10, and HOXC9, and in most cases, these differences are observed in both rodents and humans. Similar differences in development gene expression are observed in preadipocytes isolated from different adipose depots of rodents. These differences in gene expression are large in magnitude (up to 1000-fold), appear to be intrinsic, and persist during in vitro culture and differentiation, indicating that they are cell autonomous and independent of the tissue microenvironment. In addition, the authors have shown that one of these developmental genes (HOXA5) exhibit changes in expression that closely correlate with the extent of obesity (BMI) and the pattern of fat distribution (WHR). 
In recent study from Karastergiou et al. substantial differences in HOX genes expression have been found between two different subcutaneous adipose tissue depots, gluteal and abdominal. In our study, we confirm significant gene expression differences between abdominal and gluteal SAT, as well seen in the hierarchical clustering analysis. We underline differences in expression of developmental and patterning genes such as HOX genes (HOXA3, HOXA5, HOXB7, HOXB8, HOXA11, HOXA13, HOXC10, HOXC12), as previously observed.

We have also noticed as some genes, that in previous studies have been proposed as moleculare signatures of VAT, such as HOXA5 and NR2F1 appear to be up-regulated in abdominal compared to gluteal SAT (g-SAT), suggesting a similarity between VAT and abdominal SAT (a-SAT).

Furthermore, the finding that a consistent number of genes differentially expressed between gluteal and abdominal adipose depots have been previously correlated to pathogenesys of type 2 diabetes enforces our hypotesis that these depots may have a different impact in obesity associated metabolic complications.

\section{Limitations of the study}

Some limitations of the study must be underlined.

First, this research was conducted on a small sample of single sex subjects: males with an average age of 60 years old. Therefore our findings apply only to men in this specific age group.

Secondly, we adopted $>1.5$ fold change as significant threshold of differences between the two groups, as previously seen in similar researches, however this increases the possibility of false positive.

\section{Conclusions}

Our study demonstrates that subcutaneous gluteal and abdominal adipose tissue depots have distinct expression profiles. The finding of a different expression of HOX genes, fundamental during the embryo development, suggests an early regional differentiation of SAT, while the higher expression of HOXA5 and NR2F1, two molecular signatures of visceral adipocytes, in a-SAT suggests that this subcutaneous adipose depot could be more similar to VAT compared to g-SAT.

In conclusion we suggest that we should look at SAT as composed of distinct depots with possibly different impact in obesity associated metabolic complications.

\section{Methods}

Subjects enrolled in the study were partecipants the project PANGeA (Physical Activity and Nutrition for Good quality Ageing). Eight healthy middle aged men [age $60 \pm 3$ years, (57-65)] underwent subcutaneous tissue biopsy from abdomen and gluteus subcutaneous adipose tissue. Adipose tissue samples were obtained from each participant from both abdomen and gluteus. Briefly, the subject was instructed to hold in tension the muscles, so that the muscle and the fat pad were clearly recognizable. A fold from the upper outer quadrant of the buttock and from the abdomen was held between two fingers of one hand; subsequently a needle (16-17 gauge), connected to a vacutainer system, was inserted with an angle of about $45^{\circ}$ in the fat pad. After the insertion of the needle, the vacutainer tube was pressed forward to connect the vacuum with the needle. The needle was then carefully pushed back and forth 2-3 times within the fat pad to gather the adipose tissue biopsy. Subsequently the needle was immediately introduced in a sterile tube and frozen in liquid nitrogen. Adipose tissue was extracted from the needle with lysis solution (Purezool, Bio Rad, Milan, Italy) and then disrupted and homogenized using a tissue ruptor (Qiagen, Milan, Italy). RNA was isolated using Aurum Total RNA Mini kit (Bio Rad) and stored at $-80{ }^{\circ} \mathrm{C}$ until use.

All participants were medically examined prior study inclusion with an interview, routine blood analysis, and fitness battery tests. Exclusion criteria were: smoking; regular alcohol consumption; acute or chronic skeletal, neuromuscular, respiratory, metabolic and cardiovascular disease conditions. Participants were informed of the purpose, procedures and potential risk of the study before signing the informed consent. Anthropometric data were presented by body mass index and fat mass that was measured using bio impedance with a tetra-polar impedancemeter (BIA101, Akern, Florence, Italy). Blood samples were collected after an overnight fasting. Adipose tissue samples were collected by biopsy from abdomen and gluteus and immediately frozen in liquid nitrogen. Total RNA was obtained from frozen tissue samples by using the a lysis solution (Purezool, Bio Rad, Milan Italy) and successively disrupted and homogenizated using a tissue ruptor. RNA was isolated (Aurum Total RNA Mini kit, Bio Rad) and stored at $-80{ }^{\circ} \mathrm{C}$ until use. RNA labeling and hybridization on microRNA microarray chips was performed as previously described [32]. Microarray results were analysed using GeneSpring GX software 7.3 (Agilent Technologies). Data files were pre-processed using the GeneSpring plug-in for Agilent Feature Extraction software results. Data transformation was applied to set all the negative raw values at 5.0, followed by on-chip and on-gene median normalization. Filtering on gene expression was applied so that probes expressed (flagged as Present) in at least one sample were kept and probes that did not change across all samples, identified as having a normalized expression always between median \pm 1.5 , were removed. Then, samples were grouped in accordance to their status and compared. Differentially expressed genes were selected as having a 1.5-fold difference between their geometrical mean expression in the two adipose tissue 
and a statistically significant $p$ value $(<0.05)$ by ANOVA (analysis of variance), followed by application of the Benjamini and Hoechberg correction for false-positive reduction. Differentially expressed genes were employed for the cluster analysis of samples, using the standard correlation as a measure of similarity.

Finally, the list of genes differently expressed was analyzed with bioinformatics database support (DAVID gene functional classification tool) to find potential functionalrelated gene groups and gene-disease associations.

RNA quality was assessed by the use of Agilent 2100 Bioanalyzer (Agilent Technologies). Low quality RNAs (RNA integrity number below 7) were excluded from microarray analyses. Labeled cRNA was synthesized from 500 ng of total RNA using the Low RNA Input Linear Amplification Kit (Agilent Technologies) in the presence of cyanine 3-CTP (Perkin-Elmer Life Sciences, Boston, MA). Hybridizations was performed at $65{ }^{\circ} \mathrm{C}$ for $17 \mathrm{~h}$ in a rotating oven. Full dataset is available to download as Additional file 1.

\section{Additional file}

Additional file 1: Microarray complete dataset (normalized). (XLSX 7797 kb)

\begin{abstract}
Acknowledgements
The authors would like to thank Dr. Manuela Ferracin for her technical support and assistance, Dr. Daniela Francesconi, Dr. Cecilia Soavi, Dr. Eleonora Capatti for their contribution to data analysis and interpretation, and Mrs. Eletra Mantovani for her provision in administration of this project. We would like to thank the participants in the study for their time and effort to ensure the success of the project. We acknowledge the excellent assistance of the entire staff of the Orthopaedic Hospital Valdoltra (Koper, Slovenia). Additionally, we thank the research team and the students of Applied Kinesiology of University of Primorska for the help and logistic support and many other researchers and colleagues from different Institutes and different countries who contributed to the smooth undertaking of the study.
\end{abstract}

\section{Funding}

This study was a part of the research project PANGeA (Physical Activity and Nutrition for Quality Ageing), supported by a grant Cross-border Cooperation Program Slovenia - Italy 2007-2013, grant number 042-2/2009.

\begin{abstract}
Authors' contributions
Our work is a product of the intellectual environment of the whole team, all members have contributed in various degrees to its birth. Conception and design of the study - AP. Acquisition of data - AP, MLM, RP. Data analysis and interpretation -AP, JMS. Drafting of the article - AP, JMS, MAM, RC. Critical revision of the article - AP, ED, RP, JMS and GZ. All authors read and approved the final manuscript.
\end{abstract}

\section{Competing interests}

The authors declare that they have no competing interests.

\section{Ethics approval and consent to participate}

All subjets, enrolled as participants of the research project PANGeA (Physical Activity and Nutrition for Quality Ageing), gave their written informed consent. Ethical approval was obtained from the Slovenian National Medical Ethics Committee (reference number IR-Ageing 1200) on April 17th 2012. The study was conducted in accordance with the ethical standard laid down in the 1964 Declaration of Helsinki and its later amendments.

\section{Author details}

${ }^{1}$ Azienda Ospedaliero Universitaria di Ferrara, Ferrara, Italy. ${ }^{2}$ Department of Medical Sciences, Section of Internal Medicine and CardioRespiratory, University of Ferrara, Ferrara, Italy. ${ }^{3}$ Science and Research Centre, University of Primorska, Koper 6000, Slovenia.

Received: 4 June 2016 Accepted: 7 February 2017

Published online: 23 February 2017

\section{References}

1. Mokdad AH, Ford ES, Bowman BA, Dietz WH, Vinicor F, Bales VS, Marks JS, et al. Prevalence of obesity, diabetes, and obesity-related health risk factors, 2001. JAMA. 2003;289:76-9.

2. Cinti S. The adipose organ at a glance. Dis Model Mech. 2012;5(5):588-94.

3. Vague J. The degree of masculine differentiation of obesity. A factor determining predisposition to diabetes, atherosclerosis, gout and uric calculus disease. Am J Clin Nutr. 1956;4:20-34.

4. Björntorp P. Abdominal fat distribution and disease: an overview of epidemiological data. Ann Med. 1992;24:15-8.

5. Vega GL, Adams-Huet B, Peshock R, Willett D, Shah B, Grundy SM. Influence of body fat content and distribution on variation in metabolic risk. J Clin Endocrinol Metab. 2006;91(11):4459-66.

6. Fox CS, Massaro JM, Hoffmann U, Pou KM, Maurovich-Horvat P, Liu CY, Vasan RS, Murabito JM, Meigs JB, Cupples LA, D'Agostino Sr RB, O'Donnell CJ. Abdominal visceral and subcutaneous adipose tissue compartments: association with metabolic risk factors in the Framingham Heart Study. Circulation. 2007;116(1):39-48.

7. Wajchenberg BL. Subcutaneous and visceral adipose tissue: their relation to the metabolic syndrome. Endocr Rev. 2000;21:697-738.

8. Boivin A, Brochu G, Marceau S, Marceau P, Hould FS, Tchernof A. Regional differences in adipose tissue metabolism in obese men. Metabolism. 2007; 56(4):533-40.

9. Tchkonia T, Giorgadze N, Pirtskhalava T, Thomou T, DePonte M, Koo A, et al. Fat depot-specific characteristics are retained in strains derived from single human preadipocytes. Diabetes. 2006;55(9):2571-8.

10. Fontana L, Eagon JC, Trujillo ME, Scherer PE, Klein S. Visceral fat adipokine secretion is associated with systemic inflammation in obese humans. Diabetes. 2007:56(4):1010-3.

11. Strissel KJ, Stancheva Z, Miyoshi H, Perfield 2nd JW, DeFuria J, Jick Z, Greenberg AS, Obin MS. Adipocyte death, adipose tissue remodeling, and obesity complications. Diabetes. 2007;56(12):2910-8.

12. Pinnick KE, Neville MJ, Fielding BA, Frayn KN, Karpe F, Hodson L. Gluteofemoral adipose tissue plays a major role in production of the lipokine palmitoleate in humans. Diabetes. 2012;61(6):1399-403.

13. Jensen MD. Role of body fat distribution and the metabolic complications of obesity. J Clin Endocrinol Metab. 2008;93(11 Suppl 1):S57-63.

14. Schenk S, Saberi M, Olefsky JM. Insulin sensitivity: modulation by nutrients and inflammation. J Clin Invest. 2008;118(9):2992-3002.

15. Barzilai N, She L, Liu B, Vuguin P, Cohen P, Wang J, Rossetti L. Surgical removal of visceral fat reverses hepatic insulin resistance. Diabetes. 1999;48:94-8.

16. Foster MT, Shi H, Softic S, Kohli R, Seeley R, Woods SC. Transplantation of nonvisceral fat to the visceral cavity improves glucose tolerance in mice: investigation of hepatic lipids and insulin sensitivity. Diabetologia. 2011;54:2890-9.

17. Tchoukalova YD, Votruba SB, Tchkonia T, Giorgadze N, Kirkland JL, Jensen $\mathrm{MD}$. Regional differences in cellular mechanisms of adipose tissue gain with overfeeding. Proc Natl Acad Sci U S A. 2010;107(42):18226-31.

18. Hauner $\mathrm{H}$, Entenmann $\mathrm{G}$. Regional variation of adipose differentiation in cultured stromal-vascular cells from the abdominal and femoral adipose tissue of obese women. Int J Obes. 1991;15(2):121-6.

19. Marin P, Oden B, Bjorntorp P. Assimilation and mobilization of triglycerides in subcutaneous abdominal and femoral adipose tissue in vivo in men: effects of androgens. J Clin Endocrinol Metab. 1995;80:239-43.

20. Romanski SA, Nelson RM, Jensen MD. Meal fatty acid uptake in adipose tissue: gender effects in nonobese humans. Am J Physiol Endocrinol Metab. 2000;279(2):E455-62.

21. Leibel RL, Edens NK, Fried SK. Physiologic basis for the control of body fat distribution in humans. Annu Rev Nutr. 1989;9:417-43.

22. Wahrenberg $H$, Lönnqvist $F$, Arner $P$. Mechanisms underlying regional differences in lipolysis in human adipose tissue. J Clin Invest. 1989;84(2): 458-67. 
23. Shadid S, Koutsari C, Jensen MD. Direct free fatty acid uptake into human adipocytes in vivo: relation to body fat distribution. Diabetes. 2007;56(5): 1369-75.

24. Johnson JA, Fried SK, Pi-Sunyer FX, Albu JB. Impaired insulin action in subcutaneous adipocytes from women with visceral obesity. Am J Physiol Endocrinol Metab. 2001;280(1):E40-9.

25. Billon N, Dani C. Developmental Origins of the Adipocyte Lineage: New Insights from Genetics and Genomics Studies. Stem Cell Rev and Rep. 2011; 8:55-66.

26. Gesta S, Tseng YH, Kahn CR. Developmental origin of fat: tracking obesity to its source. Cell. 2007:131(2):242-56.

27. Karastergiou K, Fried SK, Xie H, Lee MJ, Divoux A, Rosencrantz MA, Chang RJ $\mathrm{R}$, Smith ST. Distinct Developmental Signatures of Human Abdominal and Gluteal Subcutaneous Adipose Tissue Depots. J Clin Endocrinol Metab. 2012;98(1):362-71.

28. Vidal H. Gene expression in visceral and subcutaneous adipose tissues Ann Med. 2001:33(8):547-55.

29. Vohl MC, Sladek R, Robitaille J, Gurd S, Marceau P, Richard D, Hudson TJ, Tchernof A. A survey of genes differentially expressed in subcutaneous and visceral adipose tissue in men. Obes Res. 2004;12(8):1217-22.

30. Gesta S, Blüher M, Yamamoto Y, Norris AW, Berndt J, Kralisch S, Boucher J, Lewis C, Kahn CR. Evidence for a role of developmental genes in the origin of obesity and body fat distribution. Proc Natl Acad Sci U S A. 2006;103(17): 6676-81.

31. Cantile M, Procino A, D'Armiento M, Cindolo L, Cillo C. HOX gene network is involved in the transcriptional regulation of in vivo human adipogenesis. J Cell Physiol. 2003;194(2):225-36.

32. Ferracin M, Gafà R, Miotto E, Veronese A, Pultrone C, Sabbioni S, Lanza G, Negrini $\mathrm{M}$. The methylator phenotype in microsatellite stable colorectal cancers is characterized by a distinct gene expression profile. J Pathol. 2008; 214(5):594-602.

\section{Submit your next manuscript to BioMed Central and we will help you at every step:}

- We accept pre-submission inquiries

- Our selector tool helps you to find the most relevant journal

- We provide round the clock customer support

- Convenient online submission

- Thorough peer review

- Inclusion in PubMed and all major indexing services

- Maximum visibility for your research

Submit your manuscript at www.biomedcentral.com/submit 